\title{
PENGARUH MOTIVASI KERJA TERHADAP KINERJA PEGAWAI PADA DIVISI KESEKRETARIATAN PT PLN (PERSERO) DISTRIBUSI JAKARTA RAYA DAN TANGERANG \\ Megido Andreas, Maswir ${ }^{1)}$ dan Mawarta Onida ${ }^{2}$ \\ Administrasi Bisnis Terapan, Politeknik Negeri Jakarta \\ Email:1'mawi.maswir@yahoo.co.id,2mawartaonida@yahoo.com
}

\begin{abstract}
This research aimed to analyze and determine the performance of employees in the Secretariat Division of PT PLN (Persero) Distribution of Jakarta and Tangerang using motivational variables are analyzed based on the theory of intrinsic motivation, according to Herzberg two-factor theory. This research was conducted to measure employee performance using several indicators, including the number (quantity) of work, quality of work, precision time, attendance, and cooperation ability. The method used in this research is the quantitative method with survey research and data collection through a questionnaire to the respondent. Processing data using a data analysis tool named SPSS (Statistical Package for the Social Sciences) version 21. The samples used in this study as many as 23 people. Based on the calculation simple linear regression analysis obtained regression equation $Y=$ $5.113+0,894 X$. From the calculation of the coefficient of determination the influence of work motivation (Variable X) on the performance (Variable Y) is equal to 0.413 or $41.3 \%$, while the remaining 0.587 or $58.7 \%$ is influenced by independent variables studied were: job satisfaction, stress, trust, justice, ethics, training and decision-making. From the calculation of significance test (partial test) can be obtained values ( $t$ count $>t$ table), i.e. $3.844>1.721$ that means Ha accepted and Ho rejected, so the hypothesis are "There is a positive and significant influence between Work Motivation and Employees Performance at Secretariat Division of PT PLN (Persero) Distribution of Jakarta and Tangerang" which means that the hypothesis can be accepted.
\end{abstract}

Key words: Performance, Work Motivation, Intrinsic Motivation.

\begin{abstract}
Abstrak
Penelitian ini bertujuan untuk menganalisis dan mengetahui kinerja pegawai pada Divisi Kesekretariatan PT PLN (Persero) Distribusi Jakarta Raya dan Tangerang dengan menggunakan variabel motivasi yang dianalisis berdasarkan teori motivasi intrinsik, menurut teori dua faktor Herzberg. Penelitian ini dilakukan dengan mengukur kinerja pegawai dengan menggunakan beberapa indikator, diantaranya jumlah (kuantitas) pekerjaan, kualitas pekerjaan, ketepatan waktu, kehadiran, dan kemampuan kerja sama. Metode penelitian yang digunakan dalam penelitian ini yaitu metode kuantitatif dengan penelitian survei serta pengumpulan data melalui kusioner ke responden. Pengolahan data dengan menggunakan alat bantu analisis data yaitu SPSS (Statistical Package for the Social Sciences) versi 21. Jumlah sampel yang digunakan dalam penelitian ini sebanyak 23 orang. Berdasarkan pada perhitungan analisis regresi linear sederhana didapat persamaan regresi $Y=$ $5,113+0,894 X$. Dari hasil perhitungan koefisien determinasi besarnya pengaruh motivasi kerja (Variabel X) terhadap kinerja (Variabel Y) adalah sebesar 0,413 atau 41,3\%, sedangkan sisanya sebesar 0,587 atau 58,7\% dipengaruhi oleh variabel bebas yang diteliti yaitu: kepuasan kerja, stress, kepercayaan, keadilan, etika, pelatihan dan pengambilan keputusan. Dari hasil perhitungan uji signifikansi (uji parsial) dapat diperoleh nilai ( $t$ hitung $>t$ tabel) yaitu 3,844 > 1,721 berarti $\mathrm{Ha}$ diterima dan Ho ditolak, sehingga hipotesis yang didapat adalah "Terdapat pengaruh positif dan signifikan antara Motivasi Kerja dan Kinerja Pegawai pada Divisi Kesekretariatan PT. PLN (Persero) Distribusi Jakarta Raya dan Tangerang.” yang berarti hipotesis tersebut dapat diterima.
\end{abstract}

Kata kunci: Kinerja, Motivasi Kerja, Motivasi Intrinsik 


\section{PENDAHULUAN}

Dalam era globalisasi yang terjadi di Indonesia akhir-akhir ini, pergerakan perekenomian nasional tentunya bisa dirasakan secara langsung oleh organisasi dan perusahaan yang dikelola oleh pemerintah atau swasta. Hal ini bisa dibuktikan dengan semakin banyaknya perusahaan baru yang mengakibatkan ketatnya persaingan usaha saat ini di Indonesia.

Pada situasi yang dialami oleh perusahaan-perusahaan sekarang ini, tidak dapat dipungkiri lagi bahwa akan timbul gejala baru khususnya dalam persaingan bisnis. Oleh karena itu perusahaan harus dapat mempertahankan keberadaan atau ke-exist-annya agar tetap dapat terus bersaing dalam memenangkan persaingan usaha serta mampu memanfaatkan peluang yang ada dengan keunggulan komparatif beserta keunggulan kompetitif yang dimiliki oleh masing-masing organisasi dan perusahaan di Indonesia. Keunggulan tersebut tentunya dapat tercipta dengan adanya pengelolaan pada manajemen sumber daya manusia yang efisien dan efektif.

Agar dapat bersaing dalam persaingan bisnis, perusahaan dituntut untuk memperoleh, mengembangkan, dan mempertahankan Sumber Daya Manusia yang berkualitas. Sumber daya Manusia sebagai penggerak organisasi banyak dipengaruhi oleh para pelaku para pesertanya, serta peran fungsinya sangat mendukung untuk keberhasilan organisasi (Agusta dan Sutanto, Jurnal Universitas Kristen Petra, 2013).

Sumber daya manusia (SDM) merupakan salah satu unsur pokok yang sangat penting, sumber daya manusia dipandang sebagai faktor pendorong utama dalam menentukan keberhasilan suatu perusahaan. Memacu motivasi karyawan harus dilakukan untuk mendorong pencapaian kinerja yang baik.
Motivasi merupakan proses pemberian motif (penggerak) bekerja kepada para pegawai sehingga mereka mau bekerja demi tercapainya tujuan perusahaan secara efektif dan efisien (Murti dan Srimulyani, Jurnal Universitas Kotolik Widya Mandala, 2013:10).

Untuk mencapai keberhasilan secara efektif dan efisien tersebut maka salah satu usaha yang bisa diberikan oleh perusahaan adalah memberikan dorongan, minat, hasrat kepada pegawai agar mereka bersedia untuk bekerja sesuai dengan apa yang diinginkan oleh organisasi. Daya dorong yang dideskripsikan diatas sebagai motivasi (Uno, 2007).

Setiap karyawan mempunyai motivasi yang berbeda dalam melakukan setiap pekerjaan yang diembankan kepadanya. Motivasi tersebut terbentuk dari sikap masing-masing karyawan dalam menghadapi situasi kerja di tempat kerja masing-masing. Kondisi atau energi yang dimiliki oleh karyawan yang membuat mereka bergerak dan bersemangat untuk mencapai tujuan organisasi atau perusahaan dan tujuan mereka sendiri adalah motivasi. Mental dan sikap optimistis terhadap situasi kerja inilah yang jika dimiliki karyawan akan membuat karyawan menjadi giat bekerja. Sebaliknya jika motivasi yang dimiliki oleh seorang karyawan rendah atau karyawan tidak memiliki semangat bekerja, serta sikap pesimistis yang karyawan miliki, maka tidak heran jika karyawan menemui hambatan dalam bekerja, maka tujuan perusahaan akan terhambat pencapaianya. Mengingat pentingnya motivasi bagi perusahaan dan karyawan, maka langkah yang diambil oleh pihak manajemen mengenai masalah motivasi karyawan ialah dengan melakukan usaha untuk memberikan motivasi kepada karyawan melalui serangkaian kegiatan yang telah ditetapkan oleh perusahaan, sehingga motivasi karyawan dalam bekerja akan tetap terjaga. Perusahaan harus mengetahui bahwa karyawan bekerja untuk memenuhi kebutuhan mereka yang beraneka-ragam, 
seperti penghasilan atau gaji yang diberikan oleh perusahaan, kepuasan pribadi dari hasil kerjanya, peningkatan status, penghargaan dari rekan sejawat, dari atasannya, dan lain-lain.

Sehubungan dengan hal diatas, motivasi merupakan hal yang sangat penting dalam suatu perusahaan, karena dapat meningkatkan kinerja dari karyawan, sehingga kemampuan manajemen dalam memberikan motivasi akan sangat menentukan keberhasilan atau kegagalan dalam mencapai tujuan perusahaan.

Berdasarkan latar belakang masalah diatas maka penulis tertarik untuk melakukan studi dengan penelitian dengan mengambil judul "Pengaruh Motivasi Kerja terhadap Kinerja Pegawai pada Divisi Kesekretariatan PT PLN (Persero) Distribusi Jakarta Raya dan Tangerang”, sebagai bahan penelitian untuk penulisan Skripsi pada Program Studi Administrasi Bisnis Terapan, pada Jurusan Administrasi Bisnis, Politeknik Negeri Jakarta.

\section{Perumusan Masalah}

Berdasarkan pada pembatasan masalah yang diuraikan di atas penulis mengidentifikasi masalah yang akan dibahas yaitu "Bagaimana pengaruh motivasi kerja pegawai terhadap kinerja pegawai pada Divisi Kesekretariatan PT PLN (Persero) Distribusi Jakarta Raya dan Tangerang”.

\section{METODE PENELITIAN}

Metode penelitian yang digunakan pada penelitian ini jika dilihat berdasarkan metode penelitian maka penelitian ini tergolong penelitian survey (lapangan). Jika dilihat berdasarkan tingkat eksplanasinya, maka penelitian ini tergolong penelitian asosiatif, dimana penelitian ini bertujuan untuk mengetahui pengaruh antara dua variabel. Jika dilihat berdasarkan jenis data dan analisisnya, maka penelitian ini tergolong penelitian kuantitatif.
Jumlah populasi pada penelitian ini adalah sebanyak 23 responden. Sedangkan teknik sampling yang digunakan adalah sampling jenuh. Teknik pengumpulan data dilakukan dengan melakukan observasi ke lapangan dan menyebarkan instrument penelitian berupa kuesioner ke responden, tipe skala yang digunakan untuk mengukur kedua variabel pada penelitian ini adalah skala interval. Data-data yang diperoleh dari pengukuran dengan menggunakan skala Likert misalnya adalah berbentuk data interval. Penggunaan skala interval dalam penelitian ini dikarenakan peneliti ingin mengetahui seberapa kuat responden setuju atau tidak setuju dengan pernyataan yang ada dalam kuesioner melalui skala likert atau skala 5 titik.

Teknik pengolahan data melalui tahapan berikut:

Editing adalah proses pengecekan atau pengoreksian data yang telah selesai dikumpulkan, karena data yang masuk (new data) terdapat data yang tidak logis atau meragukan.

Coding adalah proses pemberian kode tertentu terhadap aneka ragam kuesioner yang sama. Pada penelitian ini peneliti membuat kode dalam kuesioner.

Tabulasi adalah pembuatan tabel-tabel yang memuat data yang telah terlebih dahulu diberi kode sesuai dengan analisis yang dibutuhkan, sehingga data yang telah diperoleh dapat dihitung dengan mudah. Hal ini dilakukan agar hasil penelitian dapat dilihat dengan jelas. Setelah proses selesai, maka data-data yang telah selesai ditabulasikan tersebut akan siap untuk diolah dengan bantuan Software SPSS (Statistical Package for Social Science) version 21.0 for Windows.

Untuk uji instrumen penelitian menggunakan uji validitas dan realibilitas. Sebelum memenuhi syarat statistik parametris, digunakan uji normalitas dan uji linearitas. Untuk uji hipotesis menggunakan teknik analis regresi linear sederhana, analisis korelasi sederhana, uji determinasi dan uji parsial (uji T). 


\section{HASIL DAN PEMBAHASAN}

Berdasarkan hasil penelitian yang dilakukan, maka hasil rekapitulasi data dapat dipaparkan seperti berikut:

a. Karakteristik Responden Berdasarkan Jenis Kelamin

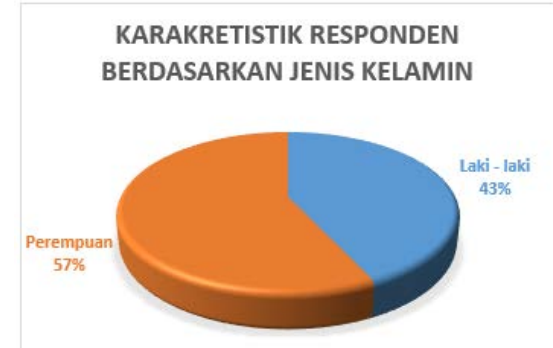

b. Karakteristik Responden Berdasarkan Usia

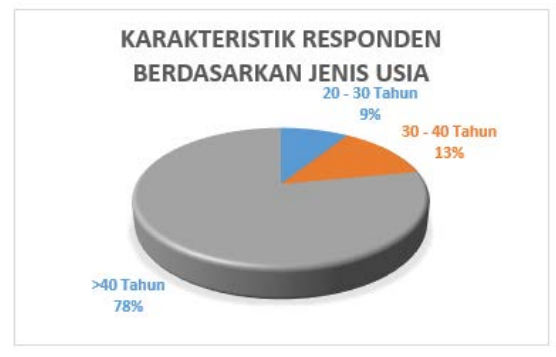

Berdasarkan hasil penelitian yang dilakukan, maka hasil uji validitas dapat dilihat pada tabel berikut:

Tabel 1. Hasil Uji Validitas Motivasi Kerja

\begin{tabular}{lccc}
\hline Pernyataan & r-hitung & r-tabel (5\%) & Keterangan \\
\hline Pernyataan 1 & 0.788 & 0,707 & VALID \\
Pernyataan 2 & 0.917 & 0,707 & VALID \\
Pernyataan 3 & 0.721 & 0,707 & VALID \\
Pernyataan 4 & 0.712 & 0,707 & VALID \\
Pernyataan 5 & 0.868 & 0,707 & VALID \\
Pernyataan 6 & 0.719 & 0,707 & VALID \\
Pernyataan 7 & 0.917 & 0,707 & VALID \\
Pernyataan 8 & 0.712 & 0,707 & VALID \\
Pernyataan 9 & 0.782 & 0,707 & VALID \\
Pernyataan 10 & 0.938 & 0,707 & VALID \\
Pernyataan 11 & 0.922 & 0,707 & VALID \\
Pernyataan 12 & 0.917 & 0,707 & VALID \\
Pernyataan 13 & 0.868 & 0,707 & VALID \\
Pernyataan 14 & 0.710 & 0,707 & VALID \\
Pernyataan 15 & 0.834 & 0,707 & VALID \\
\hline
\end{tabular}

Tabel 2. Hasil Uji Validitas Kinerja

\begin{tabular}{cccc}
\hline Pernyataan & r-hitung & r-tabel (5\%) & Keterangan \\
\hline Pernyataan 16 & 0.755 & 0,707 & VALID \\
Pernyataan 17 & 0.808 & 0,707 & VALID \\
Pernyataan 18 & 0.731 & 0,707 & VALID \\
Pernyataan 19 & 0.857 & 0,707 & VALID \\
Pernyataan 20 & 0.788 & 0,707 & VALID \\
Pernyataan 21 & 0.775 & 0,707 & VALID \\
Pernyataan 22 & 0.878 & 0,707 & VALID \\
Pernyataan 23 & 0.722 & 0,707 & VALID \\
Pernyataan 24 & 0.861 & 0,707 & VALID \\
Pernyataan 25 & 0.726 & 0,707 & VALID \\
Pernyataan 26 & 0.844 & 0,707 & VALID \\
Pernyataan 27 & 0.833 & 0,707 & VALID \\
Pernyataan 28 & 0.766 & 0,707 & VALID \\
Pernyataan 29 & 0.726 & 0,707 & VALID \\
Pernyataan 30 & 0.801 & 0,707 & VALID \\
\hline
\end{tabular}

Berdasarkan hasil penelitian yang dilakukan, maka hasil uji realibilitas dapat dilihat pada tabel berikut:

Tabel 3. Hasil Uji Reliabilitas

\begin{tabular}{ccccc}
\hline No & Variabel & $\begin{array}{c}\text { Nilai Alpha } \\
\text { Cronbach's }\end{array}$ & $\begin{array}{c}\text { Alpha } \\
\text { Cronbach's }\end{array}$ & Keterangan \\
\hline 1 & $\begin{array}{c}\text { Motivasi } \\
\text { Kerja }\end{array}$ & 0,961 & 0,600 & Reliabel \\
2 & Kinerja & 0,954 & 0,600 & Reliabel \\
\hline
\end{tabular}

Dari hasil rekapitulasi data dapat diketahui faktor-faktor yang mempengaruhi motivasi kerja dan kinerja adalah semua indikator dari masingmasing variabel dikarenakan semua indikator memperlihatkan nilai persentase jawaban responden dalam kuesioner dengan mayoritas tanggapan setuju dan sedikit yang menyatakan kurang setuju. Berdasarkan tanggapan responden terhadap motivasi kerja pegawai pada Divisi Kesekretariatan PT PLN (Persero) Distribusi Jakarta Raya dan Tangerang maka faktor yang paling besar pengaruhnya adalah keberhasilan.

Sebelum melakukan uji hipotesis terlebih dahulu dilakukan uji asumsi dasar yaitu uji normalitas dan uji linearitas. 


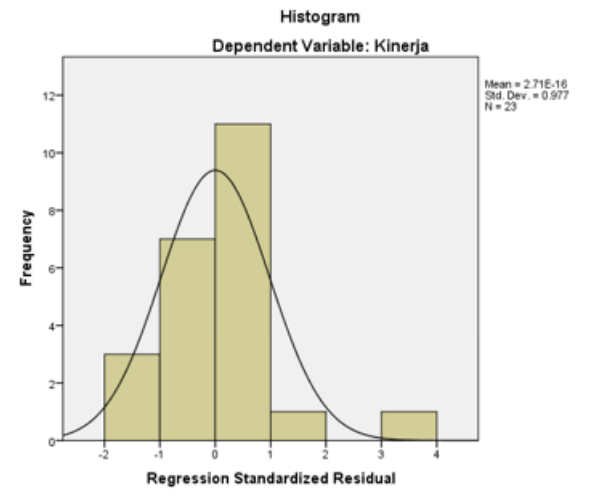

Dasar pengambilan keputusan yaitu apabila kurva distribusi normal baku berbentuk lonceng maka dapat disimpulkan bahwa pada distribusi mendekati normal. Dengan melihat kurva maka dapat diperoleh keputusan bahwa pola distribusi mendekati normal, karena kurva distribusi normal baku berbentuk lonceng.

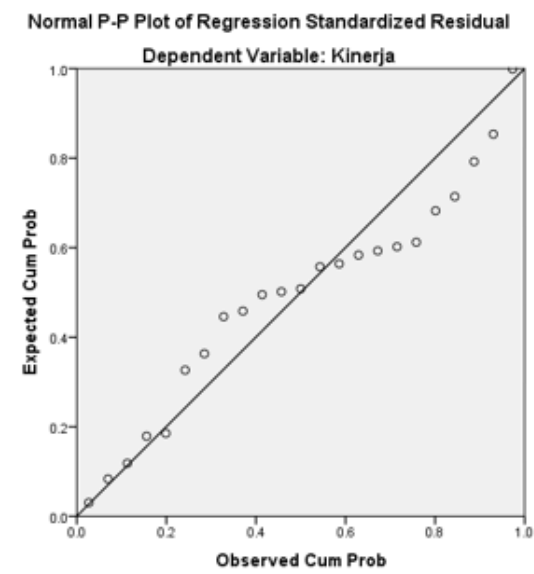

Dasar pengambilan keputusan yaitu jika data menyebar di sekitar garis diagonal dan mengikuti arah garis diagonal atau grafik histogramnnya menunjukkan pola distribusi normal, maka model regresi memenuhi normalitas. Dengan melihat tampilan grafik normal plot pada gambar diatas, maka dapat ditarik kesimpulan bahwa pola distribusi mendekati normal. Pada grafik normal plot terlihat titik-titik menyebar di sekitar garis diagonal.

Dari hasil kedua uji distribusi normal yang telah dijelaskan sebelumnya, yaitu dengan menggunakan kurva distribusi normal baku dan grafik normal plot, maka dapat disimpulkan bahwa data yang dihasilkan terdistribusi secara normal.
Tabel 4. Hasil Uji Linearitas

\begin{tabular}{|c|c|c|c|c|c|c|c|}
\hline \multicolumn{8}{|c|}{ ANOVA Table } \\
\hline & & & $\begin{array}{l}\text { Sum of } \\
\text { Squares }\end{array}$ & $\mathrm{df}$ & $\begin{array}{l}\text { Mean } \\
\text { Square }\end{array}$ & $\mathrm{F}$ & Sig. \\
\hline \multirow{5}{*}{$\begin{array}{l}\text { Motivasi } \\
\text { Kerja* } \\
\text { Kinerja }\end{array}$} & \multirow{3}{*}{$\begin{array}{l}\text { Between } \\
\text { Groups }\end{array}$} & (Combined) & 1211.217 & 14 & 86.516 & 2.837 & .071 \\
\hline & & Linearity & 601.030 & 1 & 601.030 & 19.706 & .002 \\
\hline & & $\begin{array}{l}\text { Deviation } \\
\text { from } \\
\text { Linearity }\end{array}$ & 610.187 & 13 & 46.937 & 1.539 & .275 \\
\hline & \multicolumn{2}{|c|}{ Within Groups } & 244.000 & 8 & 30.500 & & \\
\hline & \multicolumn{2}{|l|}{ Total } & 1455.217 & 22 & & & \\
\hline
\end{tabular}

Berdasarkan tabel diatas dapat diketahui bahwa signifikansi (linearity) yaitu sebesar 0,002. Nilai tersebut lebih kecil dari taraf signifikansi penelitian yaitu $10 \%(0,10)$. Dengan demikian, dapat disimpulkan bahwa antara variabel motivasi kerja (X) dan variabel kinerja (Y) memiliki hubungan yang linear.

Tabel 5. Hasil Uji Regresi Linier Sederhana

\begin{tabular}{|c|c|c|c|c|}
\hline \multicolumn{5}{|c|}{ Coefícients ${ }^{2}$} \\
\hline \multirow{2}{*}{\multicolumn{2}{|c|}{ Model }} & \multicolumn{2}{|c|}{ Unstandardized Coefficients } & \multirow{2}{*}{$\begin{array}{c}\text { Standardized Coefficients } \\
\text { Beta }\end{array}$} \\
\hline & & B & Std. Error & \\
\hline \multirow[t]{2}{*}{1} & (Constant) & 5.113 & 13.215 & \\
\hline & Motivasi Kerja & .894 & 233 & .643 \\
\hline & adent Vari & Kinerja & & \\
\hline
\end{tabular}

Adapun persamaan regresinya adalah sebagai berikut:

$$
Y=5,113+0,894 X
$$

Nilai 5,113 merupakan konstanta, artinya jika motivasi kerja (X) nilainya adalah 0, maka kinerja (Y) nilainya adalah sebesar 5,113. Sedangkan nilai koefisien arah regresi adalah positif yaitu sebesar 0,894, artinya jika ada penambahan satu nilai atau angka pada motivasi kerja (X) maka akan ada kenaikan pada kinerja (Y) sebesar 0,894.

Tabel 6. Hasil Uji Korelasi Sederhana

\begin{tabular}{|l|l|r|r|}
\hline \multicolumn{3}{|c|}{ Correlations } \\
\hline \multirow{4}{*}{ Motivasi Kerja } & Motivasi Kerja & Kinerja \\
\cline { 2 - 4 } & Pearson Correlation & 1 & $.643^{* *}$ \\
\cline { 2 - 4 } & Sig. (2-tailed) & & .001 \\
\cline { 2 - 4 } & $\mathrm{N}$ & 23 & 23 \\
\hline \multirow{3}{*}{ Kinerja } & Pearson Correlation & $.643^{* *}$ & 1 \\
\cline { 2 - 4 } & Sig. (2-tailed) & .001 & \\
\cline { 2 - 4 } & $\mathrm{N}$ & 23 & 23 \\
\hline \multirow{3}{*}{$* *$ Correlation is significant at the 0.01 level (2-tailed). } \\
\hline
\end{tabular}

Berdasarkan tabel diatas dapat diperoleh koefisien korelasi (R) antara variabel motivasi kerja (X) dan kinerja (Y) sebesar 0,643. Berdasarkan pedoman interpretasi korelasi yang telah dikemukakan oleh Sugiyono, maka dapat 
disimpulkan bahwa terjadi hubungan yang kuat antara variabel motivasi kerja (X) dan kinerja (Y).

Tabel 7. Hasil Uji Koefisien Determinasi

\begin{tabular}{|l|c|r|r|r|}
\hline \multicolumn{5}{|c|}{ Model Summary b $^{\mathbf{b}}$} \\
\hline Model & $\mathrm{R}$ & $\mathrm{R}$ Square & \multicolumn{1}{|c|}{ Adjusted R Square } & Std. Error of the Estimate \\
\hline 1 & $.643^{\mathrm{a}}$ & .413 & .385 & 6.378 \\
\hline a. Predictors: (Constant), Motivasi Kerja \\
\hline \multicolumn{4}{|l|}{ b. Dependent Variable: Kinerja } \\
\hline
\end{tabular}

Dari tabel di atas, diperoleh nilai koefisien korelasi (R) sebesar 0,643 dan koefisien determinasi ( $R$ Square) sebesar 0,413. Angka ini diperoleh dari penguadratan koefisien korelasi $(0,643 x 0,643)$ dan selanjutnya dikalikan dengan $100 \%$. Hal ini menunjukkan besarnya peran atau kontribusi variabel motivasi kinerja (X) sebesar 41,3\%, sedangkan sisanya sebesar $58,7 \%$ yang dipengaruhi oleh faktor-faktor lain yang bukan menjadi objek penelitian.

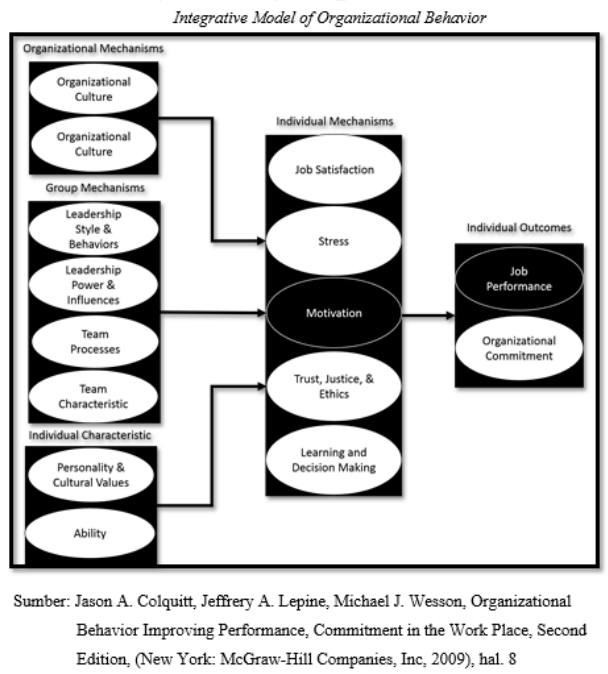

Faktor-faktor (variabel) lain yang tidak diteliti, yaitu: kepuasan kerja, stress, motivasi ekstrinsik, kepercayaan, keadilan, etika, pelatihan dan pengambilan keputusan yang juga mempengaruhi kinerja pegawai.

Tabel 8. Hasil Uji T

\begin{tabular}{|c|l|c|c|}
\hline \multicolumn{3}{|c|}{ Coefficients $^{\mathbf{a}}$} \\
\hline \multicolumn{2}{|c|}{ Model } & $\mathrm{t}$ & Sig. \\
\hline 1 & (Constant) & .387 & .703 \\
\hline & Motivasi Kerja & 3.844 & .001 \\
\hline
\end{tabular}

Diperoleh nilai $t$ hitung sebesar 3,844 yang bernilai positif. Nilai tersebut lebih besar dibandingkan dengan $t$ tabel $(a=$
5\%, 21) yaitu 1,721. Dengan demikian, dapat disimpulkan bahwa variabel motivasi kerja (X) memiliki pengaruh positif dan signifikan terhadap kinerja (Y). Maka hipotesis Ha dapat diterima.

\section{KESIMPULAN DAN SARAN}

Berdasarkan hasil penelitian dan pembahasan yang dilakukan oleh peneliti tentang pengaruh motivasi kerja terhadap kinerja pegawai pada Divisi Kesekretariatan PT PLN (Persero) Distribusi Jakarta Raya dan Tangerang, maka dapat ditarik kesimpulan sebagai berikut:

a. Berdasarkan hasil penelitian pada Bab IV, maka diperoleh persamaan regresi linear sederhana, yaitu sebagai berikut:

$\mathrm{Y}=\mathbf{5 , 1 1 3}+\mathbf{0 , 8 9 4} \mathrm{X}$

Dimana Y merupakan kinerja dan $\mathrm{X}$ merupakan motivasi kerja, yang artinya apabila pengaruh motivasi kerja (X) sama dengan 0 (tidak ada perubahan), maka kinerja (Y) tetap sebesar 5,113. Nilai 0,894X merupakan koefisien regresi yang menunjukkan bahwa setiap pertambahan satu nilai angka pada motivasi kerja (X), maka akan ada kenaikan variabel kinerja (Y) sebesar 0,894 .

b. Dari hasil analisis korelasi sederhana (R), didapatkan hasil korelasi antara motivasi dan kinerja pegawai pada Divisi Kesekretariatan PT PLN (Persero) Distribusi Jakarta Raya dan Tangerang sebesar 0,643 yang menunjukkan bahwa hubungan antara motivasi kerja terhadap kinerja masuk pada tingkatan kuat (0,600 - 0,799). Pengaruh motivasi kerja terhadap kinerja positif karena nilai $\mathrm{R}$ positif, maka motivasi kerja yang dimiliki pegawai pada Divisi Kesekretariatan PT PLN (Persero) Dsitribusi Jakarta Raya dan Tangerang sudah sebaik dan sudah terpenuhi, maka kinerja pegawai tersebut dapat menunjukkan hasil kinerja yang optimal dan dapat 
membantu perusahaan mencapai tujuanya serta dapat membawa perusahaan ke arah yang lebih baik.

c. Koefisien determinasi $\left(\mathrm{R}^{2}\right)$ menunjukkan hasil sebesar 0,413. Hal ini menunjukkan indeks determinasi, yang menyumbangkan pengaruh variabel motivasi kerja terhadap kinerja, yaitu sebesar $41,3 \%(0,413 \times 100 \%)$ dan sisanya sebesar $58,7 \% \quad(0,587 \times 100 \%)$ dipengaruhi oleh faktor-faktor (variabel) lain yang tidak diteliti, yaitu: kepuasan kerja, stress, motivasi ekstrinsik, kepercayaan, keadilan, etika, pelatihan dan pengambilan keputusan yang juga mempengaruhi kinerja pegawai.

d. Hasil Uji T (Uji Parsial) pada kedua variabel ini menunjukkan $t$ hitung sebesar 3,844 sedangkan $t$ tabel menunjukkan hasil sebesar 1,721, dimana nilai $t$ hitung lebih besar dari nilai $t$ tabel yaitu 3,844 >1,721 yang berarti $t$ hitung bernilai positif dengan probabilitas signifikansi sebesar 0,001, yang dibandingkan dengan probabilitas signifikansi sebesar 0,05, yaitu 0,001 < 0,05 maka Ha diterima dan Ho ditolak, sehingga hipotesis yang didapat adalah "Terdapat pengaruh positif dan signifikan antara Motivasi Kerja dan Kinerja Pegawai pada Divisi Kesekretariatan PT. PLN (Persero) Distribusi Jakarta Raya dan Tangerang." yang berarti hipotesis tersebut dapat diterima.

Berdasarkan kesimpulan di atas dan hasil peneltitian yang telah dilakukan oleh peneliti tentang pengaruh motivasi kerja terhadap kinerja pegawai pada Divisi Kesekretariatan PT PLN (Persero) Distribusi Jakarta Raya dan Tangerang, terdapat beberapa hal yang perlu diperhatikan oleh perusahaan yaitu sebagai berikut:

a. PT PLN (Persero) Distribusi Jakarta Raya dan Tangerang diharapkan lebih memfokuskan perhatiannya untuk usaha-usaha peningkatan motivasi kerja karyawan karena motivasi mempunyai peran atau andil yang cukup besar terhadap kinerja karyawan. Peningkatan motivasi dapat dilakukan dengan memberikan sikap positif kepada pegawai agar keberhasilan/pencapaian pegawai tersebut tercapai, memberikan pengakuan/penghargaan apabila pekerjaan yang pegawai lakukan sudah mencapai hasil yang sesuai dengan yang diinginkan oleh perusahaan, memberikan pekerjaan yang sesuai dengan jobdescription pegawai dan menempatkan pegawai dengan bidang yang sesuai dengan keterampilan dirinya, memberikan partisipasi kepada pegawai agar ikut terlibat dalam pekerjaan yang diberikan oleh perusahaan, dan memberikan pelatihan atau pengembangan kepada pegawai supaya kemampuan dan keterampilan yang dimiliki bisa menghasilkan kinerja yang lebih optimal.

b. PT PLN (Persero) Distribusi Jakarta Raya dan Tangerang merupakan perusahaan BUMN (Badan Usaha Milik Negara) yang sudah sangat lama sehingga perusahaan perlu mencari inovasi-inovasi baru, perusahaan juga dirasa perlu untuk mengadakan acara amal, kegiatan-kegiatan sosial serta acara yang memacu kreativitas pegawai agar mereka berpartisipasi dalam acaraacara yang diselenggarakan oleh perusahaan, sebagai wujud dari keterlibatan pegawai dalam mengembangkan kemampuan dan keterampilan yang mereka miliki untuk menaikkan kompetensi yang mereka miliki yang nantinya akan ditujukan bagi perusahaan.

\section{DAFTAR PUSTAKA}

Buku:

Arep, Ishak dan Hendri Tanjung. 2003. Manajemen Sumber Daya Manusia. Jakarta : Universitas Trisakti. 
Bangun, Wilson. 2012. Manajemen Sumber Daya Manusia. Bandung : Erlangga.

Colquit, Jason A., A. Lepine, and Michael J. Wesson. 2009. Organizational Behavior Improving Performance, Commitment in the Work Place, Second Edition. New York : McGraw-Hill Companies, Inc.

Dessler, Gary. 2006. Manajemen Sumber Daya Manusia, Edisi Kesepuluh. Jakarta : PT. Indeks.

Hasibuan, Malayu S.P. 2005. Manajemen Sumber Daya Manusia, Edisi Revisi. Jakarta : Bumi Aksara.

Husein, Umar. 2001. Metode Penelitian Untuk Skripsi dan Tesis Bisnis Edisi 11. Jakarta : PT. Raja Grafindo Persada.

Kountur, Ronny. 2009. Penelitian untuk Penulisan Skripsi. Jakarta : Percetakan Buana Printing.

Mangkunegara, Anwar Prabu A.A. 2008. Manajemen Sumber Daya Manusia Perusahaan. Bandung : PT. Remaja Rosdakarya.

Noor, Juliansyah. 2011. Metodologi Penelitian. Jakarta : Kencana Prenada Media Group.

Robbins, Stephen P \& Mary Coulter. 2007. Manajemen, Edisi-8, Jilid 2, Edisi Bahasa Indonesia. Jakarta: PT. Indeks.

Terry, George dan Leslie W. Rue. 2007. Dasar-Dasar Manajemen, Cetakan Kesebelas. Jakarta: PT. Bumi Aksara.

Sanusi, Anwar. 2011. Metodologi Penelitian Bisnis. Jakarta : Salemba Empat.

Siagian, Sondang P. Teori Motivasi dan Aplikasinya. Jakarta : PT. Rineka Cipta.

Siregar, Syofian. 2010. Statistik Deferentif untuk Penelitian. Jakarta : Rajawali Press.

Sperling, Abraham. 1987. "Psycology : Made Simple". New York : Mc. Graw Hill Interational.
Stanford, Fillmore H. 1969. Human Resource Management, Fourteenth Edition. New York : Mc. Graw Hill International.

Stanton, William J. 1981. Fundamentals of Marketing. New York : Mc. Graw Hill International.

Sudjana. 2000, Statistik untuk Ekonomi dan Niaga. Bandung : Tarsito.

Sugiyono. 2010. Metode Penelitian Bisnis (Pendekatan Kuantitatif, Kualitatif, dan R\&D). Bandung : Alfabeta.

-----------. 2011. Metode Penelitian Pendidikan (Pendekatan Kuantitatif, Kualitatif, dan R\&D). Bandung : Alfabeta.

Sutrisno, Eddy. 2016. Manajemen Sumber Daya Manusia. Jakarta : Prenada Media (Kencana).

Jurnal:

Agusta, Leonardo dan Eddy Madiono Sutanto. 2013. "Pengaruh Pelatihan dan Motivasi Kerja Terhadap Kinerja Karyawan CV Haragon Surabaya". Surabaya : Universitas Kristen Petra.

Murti, Harry dan Veronika Agustini Srimulyani. 2013. "Pengaruh Motivasi Terhadap Kinerja Pegawai dengan Variabel Pemediasi Kepuasan Kerja Pada PDAM Kota Madiun”. Madiun : Universitas Katolik Widya Mandala Madiun.

Sungkono, Rachmat Hasbullah, Herru Bambang Rumansyah. 2011. "Pengaruh Motivasi Terhadap Kinerja Karyawan di Outlet PT. Sinarmas Multifinance Cabang Telagasari, Karawang”. Karawang : Jurnal Manajemen.

Publikasi Elektronik:

http://www.pln.co.id/disjaya/?p=62 di akses pada 08 Agustus 2016 